\title{
Introduction for the Special Issue in memory of Manfred Schocker
}

Received: 14 May 2008 / Accepted: 20 May 2008 / Published online: 31 May 2008

(C) Springer Science+Business Media, LLC 2008

Manfred Schocker was a man full of life: he was dynamic and cheerful; he was "a force of nature". It is difficult to imagine that he is with us no more. It is especially difficult when we look at his photographs. We can but stare, without understanding. This volume of Journal of Algebraic Combinatorics is intended as a tribute to him, a way to pay our respects.

Manfred comes from the algebraic combinatorics group at Kiel in the north of Germany. Manfred's adviser was Hartmut Laue and Manfred, Laue, Dieter Blessenohl and Armin Jöllenbeck, a co-student of Manfred, worked together often. Legend has it that they met in the university cafeteria where they explored and discussed a broad spectrum of mathematics. It was certainly a very special atmosphere. According to Laue, Manfred, as a student, carried the energy into the night, and worked very late. He continued this late night working pattern throughout his career, in Montreal, Oxford and Swansea.

After his PhD in Kiel in 2001, Manfred went to Montreal for one year, in a postdoctoral position under Christophe Reutenauer, and then to Oxford for two years, with Karin Erdmann. Thus he moved overseas twice in one year, with the whole family, his wife Ingke, and their sons Lasse and Bosse. After that he obtained a position at the University of Swansea, in Wales.

Be it the Solomon Algebra, the Free Lie Algebra or Character Theory, Manfred had a deep insight in all the subjects he considered, the kind of insight one develops when one thinks very often about a subject and tries to solve all the problems that may arise, great and small. He was both a great theoretician and a great calculator.

Manfred's work contains deep results on, among other things, the descent algebra, the free Lie algebra and noncommutative character theory of the symmetric group. He wrote a remarkable book on this latter subject with Blessenohl, which appeared in 2005, and where Jöllenbeck's theory was explained and developed. A second volume was in preparation. 
Manfred explored, alone or with co-authors, the beautiful links between combinatorics and algebra. In one result, obtained in his early work in collaboration with Jöllenbeck, they showed elegantly how to take advantage of the major index in Klyachko's idempotent, introduced in the 70's. The Klyachko idempotent is an element of the group algebra of the symmetric group where the coefficient of a permutation depends on its major index, a combinatorial statistic introduced by MacMahon at the beginning of the 20th century which is now a central concept for many combinatorialists. Manfred and Armin showed how the Klyachko idempotent may be used to compute the multiplicities of the irreducible representations of the symmetric group in the Lie representation and thus explain the formula of KraskiewiczWeyman which involves the major index of Young tableaux. The results of Klyachko and Kraskiewicz-Weyman had been known independently for 10 years and the problem of relating them was a good one. It is exactly that problem that was answered by Manfred and Armin.

Another remarkable result obtained by Manfred, together with Dieter Blessenohl and Christophe Hohlweg, is the symmetry of the Solomon homomorphism; the latter maps the descent algebra of a finite Coxeter group onto its character ring.

Manfred wrote many articles in his short career: 23 according to Mathematical Reviews. The present volume contains one of Manfred's unfinished papers (written up by Nantel Bergeron) and also an article he wrote with Frédéric Patras, which was finished and accepted before his death.

Let us quote Pr. Aubrey Truman, of the University of Swansea, in his address in 2006: "I only knew Manfred for just over 2 years but it was already obvious to me that he was a star. In my department there are many brilliant researchers, many gifted teachers who really care about their students and many wonderfully warm human beings. Manfred had all these qualities and in addition he had a charismatic personality. It is no exaggeration to say that he was loved by students and staff alike. His smiling eyes with their perpetual twinkle would disarm anyone. He had the advantage of being young and good looking and was even awarded a certificate by the students last summer for being the best dancer on our staff. The students found him irresistible and gravitated towards his courses and projects."

The sudden death of Manfred in 2006 is a tragedy for us, for his family, and for the mathematical community.

Nantel Bergeron, Frédéric Patras, Arun Ram, Christophe Reutenauer Guest Editors 